This is the author's final version of the work, as accepted for publication following peer review but without the publisher's layout or pagination.

The definitive version is available at

https://doi.org/10.1016/j.jclepro.2018.03.197

\title{
Drivers, opportunities and barriers for a retailer in the pursuit of more sustainable packaging redesign
}

Jorge Ubirajara Gustavo Jr., Universidade do Vale do Rio dos Sinos, UNISINOS University, Unisinos Avenue, 950 , S.

Leopoldo, Rio Grande do Sul, Brazil.jorgegustavojr@gmail.com

Andrea Vargas, Universidade do Vale do Rio dos Sinos, UNISINOS University, Unisinos Avenue, 950, S. Leopoldo, Rio Grande do Sul, Brazil. andreavargas03@yahoo.com.br

Giancarlo Medeiros Pereira*, Universidade do Vale do Rio dos Sinos, UNISINOS University, Unisinos Avenue, 950, S.

Leopoldo, Rio Grande do Sul, Brazil. gian@unisinos.br

Alan James Bond, School of Environmental Sciences, University of East Anglia, Norwich, United Kingdom; School of Geo and Spatial Science, North-West University Potchefstroom Campus, Private Bag X6001, Potchefstroom, South Africa. alan.bond@uea.ac.uk

Claudia Viviane Viegas, Universidade do Vale do Rio dos Sinos, UNISINOS University, Unisinos Avenue, 950, S. Leopoldo, Rio Grande do Sul, Brazil. claudiavv@unisinos.br

Miriam Borchardt, Universidade do Vale do Rio dos Sinos, UNISINOS University, Unisinos Avenue, 950, S. Leopoldo, Rio Grande do Sul, Brazil. miriamb@unisinos.br

*corresponding author 


\section{Drivers, opportunities and barriers for a retailer in the pursuit of more sustainable packaging redesign}

\section{Abstract}

Redesign can reduce the environmental impact generated by product packaging. The literature presents the elements to be observed in a packaging redesign, as well as the important role of the retailer in delivering more sustainable outcomes through consideration of product packaging. However, the literature is almost silent on the motivations, opportunities and barriers faced by the retailers that try to improve the packaging of the items sold in their stores. To fill this gap, a case study approach was adopted which investigated a global supermarket chain through interviews with senior management and participant observation. Findings suggest that the greatest motivation to the packaging redesign seems to be the economic gains (for the supermarket and its suppliers), which cogenerate environmental gains. The opportunities include the adjustment of the packaging size or type. Sizes could be increased when consumers buy more than one package during a single visit to the supermarket, or reduced when consumers discard part of a perishable product without consuming it (due to over-large packaging). Barriers result from commercial uncertainties associated with: how the new packaging will affect the sales of other items? How the new design will influence the number of times that a consumer visits the supermarket? And how the new design will affect the amount of money spent by the consumer on each visit? Further studies could investigate: how to mitigate these uncertainties? How to leverage sustainability based on the economic focus? How to identify redesign opportunities among thousands of sold items? And how to better convince the suppliers that reject the supermarket proposals? The understanding developed from the case study has facilitated the derivation of a number of propositions aiming to leverage sustainability gains from packaging redesign in practice.

Keywords: Packaging redesign, sustainable packaging, sustainable production, sustainable consumption, retail, supply chain, supermarket. 


\section{Introduction}

Packaging is subject to life cycle impacts associated with the extraction of raw materials and with manufacturing, transportation, and post-consumption disposal. Furthermore, the growth of consumption has increased the environmental impacts caused by packaging production, which generates solid wastes, industrial effluents, atmospheric emissions, noise, and vibrations (Riegel et al., 2012). We define sustainable packaging after the Sustainable Packaging Coalition (SPC) as that which:

"A. Is beneficial, safe \& healthy for individuals and communities throughout its life cycle.

B. Meets market criteria for performance and cost.

C. Is sourced, manufactured, transported, and recycled using renewable energy.

D. Optimizes the use of renewable or recycled source materials.

E. Is manufactured using clean production technologies and best practices.

F. Is made from materials healthy throughout the life cycle.

G. Is physically designed to optimize materials and energy.

H. Is effectively recovered and utilized in biological and/or industrial closed loop cycles." (SPC, 2011).

This definition is a pragmatic one developed by a coalition of companies covering the supply chain and can therefore be contested. Nevertheless, in the context of our research, it allows us to define an improvement in the sustainability of packaging as an improvement in any of the criteria in the SPC (2001) definition (assuming no deterioration in others). In order to achieve such benefits, companies should design packages that protect the food properly and allow the consumer to fully use the product (Silvenius et al., 2014; Williams and Wikström, 2011). Packaging that meet these targets can also help to leverage consumer satisfaction (Williams et al., 2008). 
Any intended packaging improvement should consider consumers' perceptions, behaviors and habits (Nordin and Selke, 2010; Wikström et al., 2016; Williams et al., 2012), consumers' personal norms, attitudes, environmental concerns and willingness to pay (Prakash and Pathak, 2017), and the relationship between the size of packaging and the amount of product actually consumed (Hanssen et al., 2017). The packaging redesign may also require dialogue and engagement among producers, retailers and consumers (Hyde et al., 2001). Actors in the supply chain must collaborate (Leppelt et al., 2013) based on transparency of information considering quality management, process controls and shelflife management (Mena et al., 2014). Other actions helping to achieve environmental improvements in packaging include: better distribution packaging aiming at reducing damage in transport and handling (Verghese et al., 2015); and the optimization of the life cycle impacts of the packaging materials (Bertolini et al., 2016; Ingrao et al., 2017).

Retailers have a privileged position in the reduction of packaging amounts, in which they engage the assistance of their suppliers and customers to lesser and greater degrees (Delai and Takahashi, 2013; Erol et al., 2009; Jones et al., 2005). It happens because they pursue profit maximization and cost reduction (Glover et al., 2014), and because some of them want to deliver a positive impact on consumer store choice (Hampl and Loock, 2013). In a stricter sense, some authors suggest zero-packaging stores should be launched, comparable to conventional supermarkets, to achieve significant environmental and social benefits (Beitzen-Heineke et al., 2017).

Despite the valuable work performed by researchers, the literature is almost silent on the packaging alternatives available to, and barriers faced by, the retailers that try to improve the packaging of the items sold in their stores, as well as about the actions that can mitigate such barriers. Aiming to fill this gap, this study investigated the Brazilian branch of a global supermarket chain that operates in more than 30 countries and has a multi-billion US\$ turnover per year. All significant redesigns carried out by a large organization must be approved by the senior managers, so the inquiry of the study is targeted at this group of professionals, which is rare in academic literature. The following research question guided the investigation: 
$R Q$ - What are the motivations, opportunities and barriers faced by retailers to effectively redesign more sustainable packaging for the products they sell?

It is expected that the findings can be used by other retailers when redesigning packaging with their suppliers. The findings also facilitate questions for future research, as well formulating sixteen propositions for further studies. 


\section{Literature review}

\subsection{Benefits of a packaging redesign}

Research findings in academic literature suggest that waste reduction in the food and drinks industry can make significant contributions to company profitability by improving yields per unit output and by reducing costs associated with waste disposal (Hyde et al., 2001). A packaging design that supports a decrease in food losses can help to increase consumer satisfaction and, at the same time, reduce the environmental impact of the food-packaging system (Williams et al., 2008). Similarly, packaging that prevents food waste can help to reduce the total environmental impact, even if there is an increase related to the impact of the packaging itself (Williams and Wikström, 2011). Packaging solutions that minimize the generation of wastes in the consumers' households as well as in distribution and retail can lead to the most efficient reduction of environmental impacts in the product-packaging chain. Therefore, it is important to design packages that adequately protect the food and allow the consumer to completely use the packed product (Silvenius et al., 2014).

\subsection{Requirements beyond the corporate boundaries}

The consumers' perceptions, behaviors and habits should be considered in redesigning packaging; it is pivotal to a better understanding of consumers' perceptions about the social dimension of packaging sustainability (Nordin and Selke, 2010). According to Williams et al. (2012), around 20 to $25 \%$ of household food wastes could be related to its packaging. These authors highlight packages that the consumer noted as being too big; packages that were difficult to empty; and wasted packages because of expiry of "best before date".

The consumer behavior in households should be considered in the packaging design, since it brings indirect environmental impacts. The amount of food waste caused by package size or attributes, and the recyclability of these materials, demand considerable attention (Wikström et al., 2016). In India, the motivation for ecofriendly purchasing is significantly 
influenced by personal norms, attitudes, environmental concerns and willingness to pay, which brings consequences for package design (Prakash and Pathak, 2017). In Norway, ready-to-eat meals are sold in large packages, therefore, reducing the size of packages can reduce transport costs, energy consumption, and greenhouse gas emissions (Hanssen et al., 2017).

Attention to the supply chain is also required, therefore dialogue among producers, retailers and consumers to promote changes in primary and secondary food packaging is recommended (Hyde et al., 2001). Leppelt et al. (2013) found that the scope of corporate environmental strategies shifted from improving internal environmental performance to reducing the environmental footprint of the product chain in collaboration with actors along the supply chain. More specifically, the connection between packaging design and food waste should be acknowledged and valued by relevant stakeholders, such as: food producers; manufacturers; brand owners; retailers; and consumers, and also in packaging regulations (Wikström et al., 2014). In this context, the companies seem to invest in supplier relationship management practices aiming to manage sustainability beyond their corporate boundaries (Thongplew et al., 2014).

A set of criteria should be observed when packaging redesign needs to involve several actors. The management practices that trigger waste in food networks are related to the transparency of demand information, quality management, process controls, shelf-life management and packaging design; thus, they provide insight into the actions required to mitigate the environmental impact of food production (Mena et al., 2014). Regardless of the effectiveness of cooperative activities such as supplier development and supplier integration, supplier monitoring does not seem to positively influence supplier performance (Akamp and Müller, 2013). The packaging industry faces barriers like the lack of adequate training and progress monitoring, poor consumer awareness, and absence of pressure for a widespread adoption of green supply chain management (Wang et al., 2016). A wider adoption of zero packaging would depend on: influencing consumer behavior, convincing suppliers to change their packaging practices; and solving the dependency of food logistics on packaging (Beitzen-Heineke et al., 2017). 


\subsection{Materials, design, governance, frameworks and methods}

A product life cycle assessment (LCA) identified that a more wide-ranging integrated approach, encompassing economic, social and environmental considerations, jointly with more efficient packaging design, which save on material and are recyclable, is the key to sustainable packaging (Lee and $\mathrm{Xu}, 2005$ ). For instance, a change in packaging materials of 13 Italian tomato-based products contributed to a reduction in their weight (Del Borghi et al., 2014), whilst a multilayer carton system was found to be the least environmentally impacting alternative for extended shelf-life milk (Bertolini et al., 2016). LCA was used to analyze the foamy Polylactic Acid (PLA) trays for fresh-food packaging applications with results indicating that the highest environmental impacts come from the production and transport of the granules, so highlighting the need to identify alternative biopolymers (Ingrao et al., 2017).

Some opportunities to reduce or recover food loss and waste through improved packaging have been identified in the literature: the improvement of product protection, ventilation and temperature control; redesign of distribution packaging to reduce damage in transportation and handling; changing the design of primary packaging to reduce waste at home; and the use of retail-ready packaging that minimizes handling and improves stock rotation in stores (Verghese et al., 2015). The improvement of the environmental design of the corrugated container through four ex ante design stages, and two ex post facto supply chain stages was also suggested (Dominic et al., 2015).

The literature also presents studies focused on governance, frameworks and emergy. Findings suggest that the enforcement of retailer-defined environmental requirements, supplier improvement programs based on performance benchmarking and the dissemination of better management practices, are alternative approaches that may be used in combination with third-party certification (Styles et al., 2012). Evaluation of packaging design within a broader sustainability framework was also proposed for increasing the functionality of 
alternative bags; their relative cost; convenience for consumers and retailers; and the availability of reuse and recovery systems (Lewis et al., 2010). Another framework was suggested to guide the design of sustainable food packaging considering the entire life cycle of the product-package combination (Grönman et al., 2013). Furthermore, a method for improving the existing Tetra Pak design and development is available. It is based on an expanded operational life cycle perspective that includes the entire supply chain (Sohrabpour et al., 2016). Emergy has also been used to analyze Brazilian packaging. One study identified that PET bottles are the best option for beverage packages (Almeida et al., 2010), whilst another one identified that refillable glass bottles are the best option according to the resources available in the country (Almeida et al., 2017).

\subsection{Summary}

From the literature review, a codification approach for analyzing qualitative text was employed as proposed by Saldaña (2015). No specific tool was adopted, other than a logical codification of nouns and adjectives found in the peer-reviewed studies. In a first round, twenty-three $1^{\text {st }}$-order codes were identified. A further analysis of these codes resulted in the grouping of the $1^{\text {st }}$-order codes into $2^{\text {nd }}-$ order - conceptual- codes. The outcomes of $2^{\text {nd }}$ order codes are: benefits of a packaging redesign; requirements beyond the corporate boundaries; and materials, design, governance, frameworks and methods. The analysis of such coding suggests that the literature is almost silent on the alternatives and barriers faced by the retailers that try to improve the packaging of the items sold in their stores, as well as about the actions that can mitigate such barriers. These $1^{\text {st }}$ - and $2^{\text {nd }}$-order codes are presented in Table 1. 
Table 1 - Literature codification.

\begin{tabular}{|c|c|}
\hline $1^{\text {st }}$-order codes & $2^{\text {nd }}$-order codes \\
\hline $\begin{array}{l}\text { Improvement in the yields per unit output and cost } \\
\text { reduction (Hyde et al., 2001); increase in consumer } \\
\text { satisfaction (Williams et al., 2008); and reduction in the } \\
\text { environmental impact (Silvenius et al., 2014; Williams } \\
\text { et al., 2008; Williams and Wikström, 2011). }\end{array}$ & $\begin{array}{l}\text { Benefits of a packaging } \\
\text { redesign }\end{array}$ \\
\hline $\begin{array}{l}\text { Consideration of the consumers' habits and perceptions, } \\
\text { which includes the size of the packaging (Hanssen et al., } \\
2017 \text {; Nordin and Selke, 2010; Wikström et al., 2016; } \\
\text { Williams et al., 2012); personal norms, attitudes, } \\
\text { environmental concerns and willingness to pay } \\
\text { (Prakash and Pathak, 2017). }\end{array}$ & $\begin{array}{l}\text { Requirements beyond the } \\
\text { corporate boundaries }\end{array}$ \\
\hline $\begin{array}{l}\text { Dialogue and collaboration between producers, retailers } \\
\text { and consumers (Hyde et al., 2001; Leppelt et al., 2013; } \\
\text { Thongplew et al., 2014; Wikström et al., 2014). } \\
\text { Transparency of demand information, quality } \\
\text { management, process controls, shelf-life management } \\
\text { and packaging design (Mena et al., 2014). }\end{array}$ & \\
\hline $\begin{array}{l}\text { Training (Wang et al., 2016); and progress monitoring } \\
\text { of suppliers (Akamp and Müller, 2013; Wang et al., } \\
\text { 2016). }\end{array}$ & \\
\hline $\begin{array}{l}\text { Packaging improvements require change or } \\
\text { improvements in the materials used (Bertolini et al., } \\
\text { 2016; Del Borghi et al., 2014; Ingrao et al., 2017), } \\
\text { design (Lee and Xu, 2005); and properties (Dominic et } \\
\text { al., 2015; Verghese et al., 2015). } \\
\text { Other actions include performance benchmarking, } \\
\text { dissemination of better management practices and third- } \\
\text { party certification (Styles et al., 2012). }\end{array}$ & $\begin{array}{l}\text { Materials, design, } \\
\text { governance, frameworks } \\
\text { and methods }\end{array}$ \\
\hline
\end{tabular}


The analysis of Table 1 indicates that a better packaging design/redesign requires a combination of actions that may: embrace the external demands (consumers, retailers and suppliers); facilitate technical improvements (on materials, design or properties); and lead to the adoption of better management practices. Figure 1 summarizes these requirements.

Figure 1 - Requirements for a better packaging design/redesign.

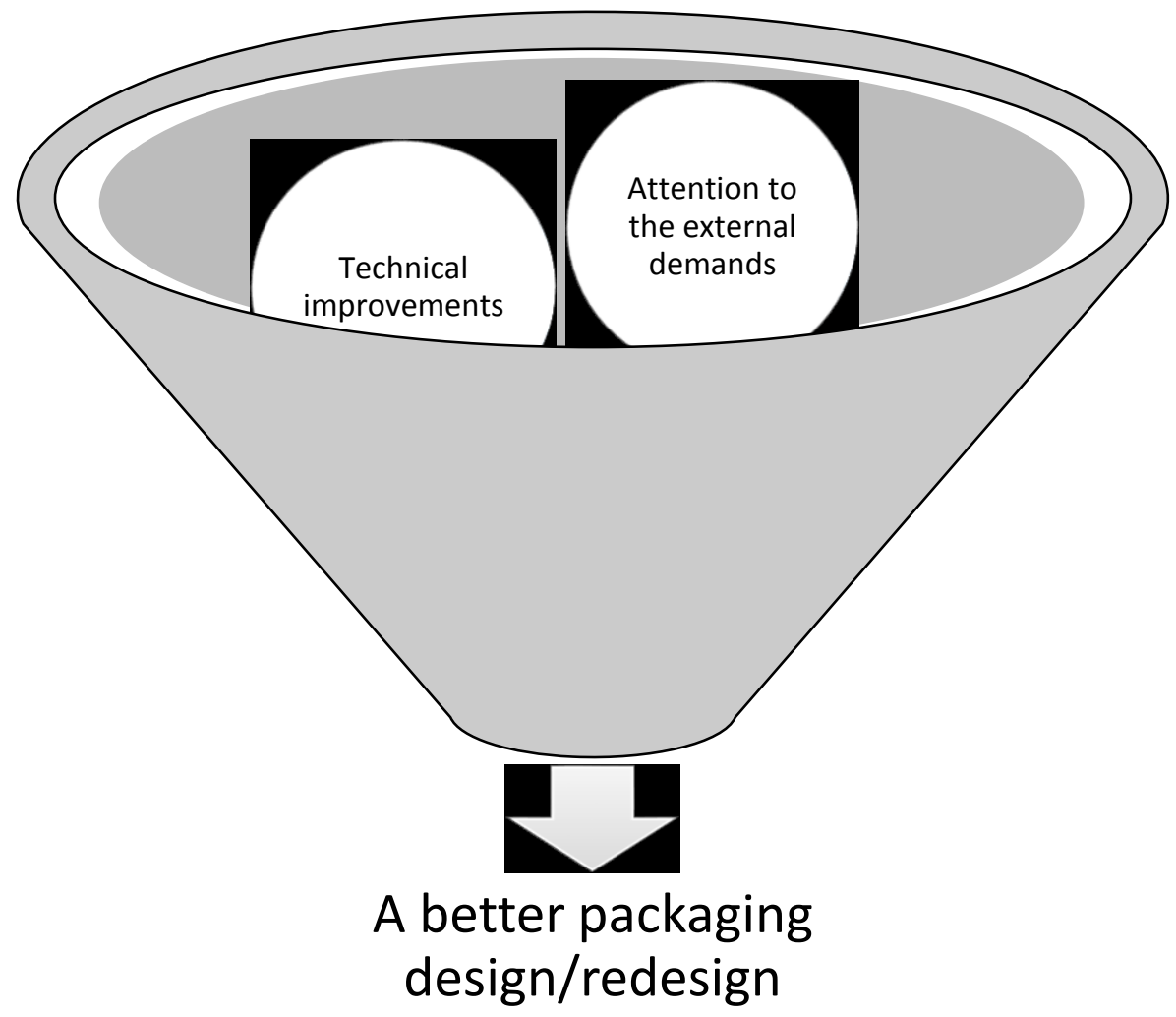




\section{Methods}

\subsection{Research design}

The research undertaken addresses a gap identified in the literature. As such, it is exploratory in the absence of theoretical understanding or hypothesis building. The research therefore functions to develop research propositions for further exploration. In order to answer the research question, a case study method was selected to explore conceptual contributions as one of the main research goals (Eisenhardt and Graebner, 2007; Yin, 2009). A case study method enables the investigation of a phenomenon within a real contemporary context through an in-depth analysis of one or more objects, thus allowing broad and detailed knowledge of the phenomenon under investigation. It embraces interviews, documentary analysis and observations. This evidence enables the triangulation of findings (Yin, 2009).

According to the prescriptions of the case study method, the interviews were based on semistructured questions. Such questions are used to start a conversation. Once an interviewee starts to talk, he/she usually provides lots of information that helps to enrich the findings, as well as to unveil practical elements that will be used to establish the contribution of the study to the literature (Yin, 2009). The coding presented in Table 1 helped to define the semi-structured questions posed to the interviewees (see Appendix A). The "Benefits of a packaging redesign" content was used to develop questions 1 and 4 . The "Requirements beyond the corporate boundaries" content was used to develop questions 2, 3, 5, 6 and 7 . The content of the "Materials, design, governance, frameworks and methods" was used to develop question 8 . 
The Brazilian operation of the supermarket targeted as a case study started 30 years ago, selling to the price-sensitive market. Currently it has more than 500 stores (of different sizes). The smaller neighborhood stores sell around 2,500 items (food, hygiene items, cleaning products, vegetables and fruits), the medium-sized stores sell around 15,000 items, whilst the largest stores sell more than 65,000 items (including food, electronics, textiles, housewares, toys, stationery, pet supplies, cleaning products and gardening essentials). The environmental policy of the company focuses on zero-waste generation, the use of renewable energy, and the sale of products that sustain both economic and environmental resources. Based on this policy, the supermarket must use its power to create a more sustainable value chain.

One researcher engaged in this investigation works as a middle manager in a Brazilian branch of this retail corporation (a supermarket), and he was responsible for collecting relevant information before and during the study. This privileged position explains the ability of this study to reach senior managers, thereby acquiring perspectives that otherwise would be difficult to obtain. The supermarket welcomes investigations that help to improve its sustainability, or to spread good practice among its employees. This company's stance further created the necessary conditions to promote the engagement of the senior executive in the study. Other information collected by the middle manager before the study had helped to justify the case selection (e.g., packaging redesigns already implemented). These redesigns had contributed to the reduction of wastes (either generated in the supply chain or by the consumers) associated with poor packaging design. The selection of the case study based on these conditions improves the robustness of the findings and increases the likelihood of valid generalization (Seawright and Gerring, 2008). 


\subsection{Participant observation}

Participant observation can enhance the researchers' understanding of the topics being analyzed (Yin, 2009). Because one of the researchers worked as a middle manager in the supermarket chain under investigation, performing these observations has facilitated the collection of evidence. This middle manager attended 45 meetings between the supermarket managers and the suppliers' representatives (sales staff or managers) aiming to perform the observations (which equates to 60 hours of observations). Before the meetings, he always informed the participants about the purpose of the observation in the meetings. The meetings were focused on the analysis of the results of the packaging redesigns already developed in the past by the supermarket chain (details are given in the findings section), or under analysis for further implementation. Brainstorming sessions and discussions regarding the design of new marketing actions to be implemented by the company were subject to participant observation. No tape recording was allowed in these meetings, which served to confirm some information collected in the interviews (for example, constraints and mitigation alternatives considered in new redesigns under analysis). This middle manager (in a diary) documented non-confidential information collected during such observations and sent it to the researchers that do not work for the supermarket. These researchers then analyzed the collected information. Such analyses unveiled topics that were then investigated in detail. 


\subsection{Qualitative expert interviews}

In the company investigated, four senior managers are responsible for all sustainability actions developed in Brazil. They were personally invited by the middle manager (and researcher) and one other researcher. All the senior managers contacted agreed to participate in the study. Manager A had been working at the company for 15 years as Director of Sustainability, which encompasses the whole supply chain and consumers. Manager B had been working for three years as Director of Environmental Projects, which focused on the supermarket's stores. Manager C had been working for 16 years as Director of Sales and Marketing. Manager D had been working for 21 years as Director of the Operations Department. Together, Managers A, B, C and D were responsible for a budget of US\$26 billion/year.

Data were gathered through 16 interviews conducted throughout the research because each manager was interviewed four times. All interviews with the senior managers were performed in English in which both managers and interviewees are fluent. During the first round of interviews, the researchers posed questions associated with the packaging and associated wastes. During the second round, they posed questions related to consumers. The third round of interviews then focused on questions regarding the supply chain, and in the fourth round the findings were discussed with the interviewees. The shortest personal interview lasted one hour, while the longest lasted 2 hours. A total of 27 hours of formal interviews were conducted in this stage. Tape recording was not allowed by the interviewees. Seven interviews had to be rescheduled due to conflicting appointments. 
Following each interview, the researchers wrote an initial report about their perceptions and conclusions. These elements were then discussed by the research team. Any remaining or unanswered questions were discussed with the interviewees before the next round. Field observations were performed by all researchers to gain more knowledge about the topics being analyzed. These observations included visits to the stores and warehouses. Considering that the packaging redesigns analyzed had been implemented, these observations were used to check the physical aspects of the new packaging, as well as their storage and transportation.

\subsection{Data analysis}

The information gathered (e.g., interview transcripts, participant observations, and documents) was analyzed using content analysis (Mayring, 2014, 2003). The analyses of the data collected enabled their classification into meaningful categories in accordance with the research question. Based on the information collected, an inductive approach was used in the codification of the findings. The combination of internal documents, publicly available material, and data gathered in interviews enabled a data source triangulation, which ensured the reliability and construct validity of the findings (Gibbert and Ruigrok, 2010; Yin, 2009). The reliability of the data was further confirmed by ensuring that the research methodology was transparent and trackable through the use of a semi-structured interview guide combined with detailed interview descriptions and the verification of all transcripts and case study documents collected during the study (Kowalkowski et al., 2013; Yin, 2009). The conclusions were submitted to the respondents for approval. This action aimed to improve the information gathered as well as assured ethical conduct of the research (Saunders et al., 2009).

Two different strategies underpinned a meaningful data interpretation. The first one focused on the "redesigns developed": what motivates the company to redesign the packaging; how a redesign opportunity can be identified; and how a redesign opportunity can be leveraged? A second one focused on "redesigns that faced problems, which either did or did not block, their implementation": why a redesign can be blocked and how to remove such a barrier (Savin-Baden and Major, 2013)? Coding was performed by hand (i.e. without using specific 
software) and led to the generation of twenty-three $1^{\text {st }}$-order codes consisting of nouns and adjectives. A further analysis of these codes aided the grouping of the $1^{\text {st }}$-order codes into $2^{\text {nd }}$-order -conceptual- codes reflecting the research question attributes of motivation, opportunities and barriers (Saldaña, 2015). The discussion of findings was based on the $2^{\text {nd }}$ order codes. Figure 2 presents the research stages followed in the study.

Figure 2 - Research stages.

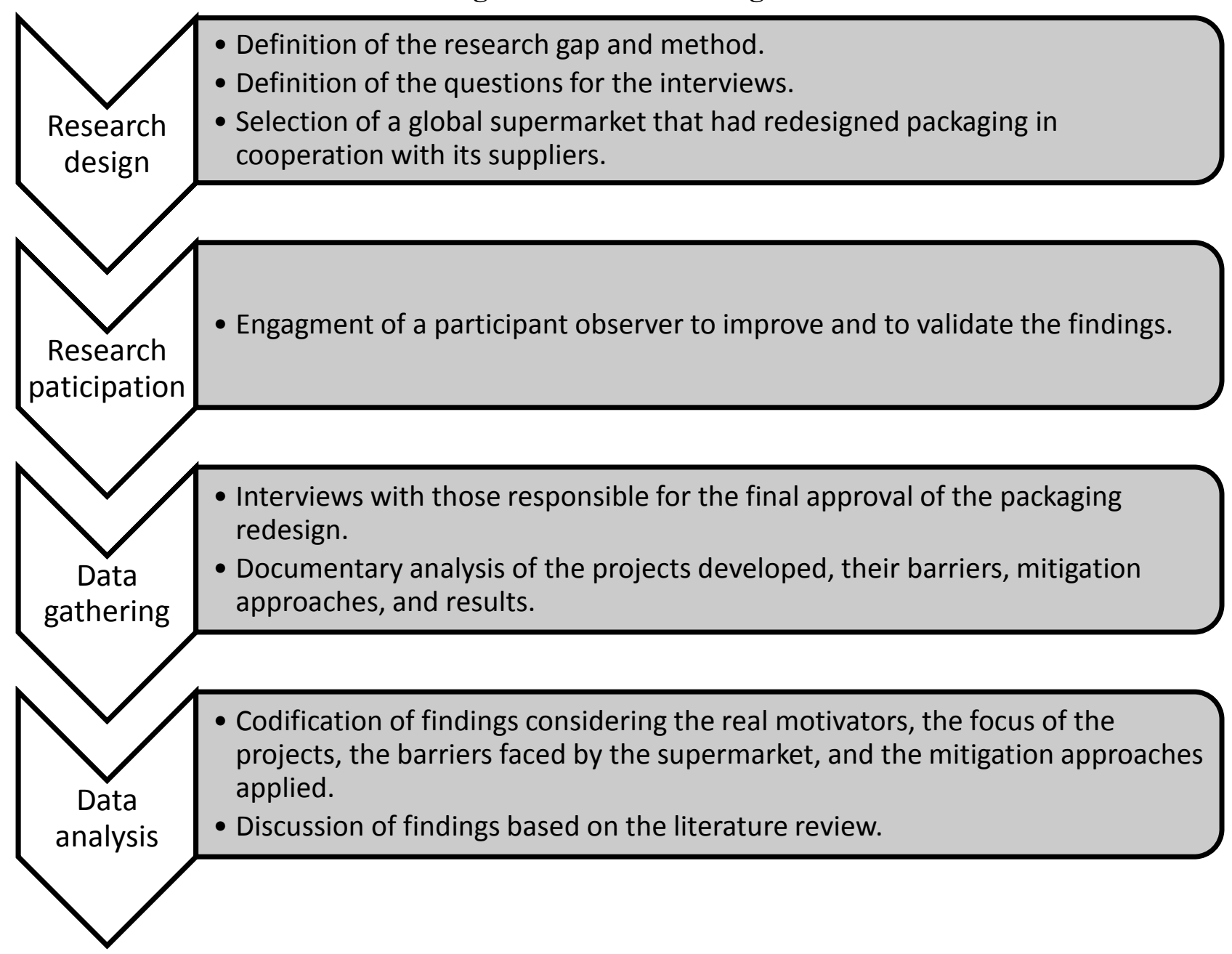




\section{Findings}

The $1^{\text {st }}$-order and $2^{\text {nd }}$-order codes that resulted from the inductive data analysis indicated three groups of findings. The first group is related to the motivations that induced the supermarket to focus on sustainability. Beyond the information usually released by the company to the media, a great motivator seems to be the desire to achieve the objective of combining economic gains with environmental sustainability. The second group of findings is related to the opportunities identified by the supermarket to meet this objective. According to the senior managers interviewed, some opportunities are related to the adjustment of the packaging size. In two cases, the packaging size was increased (powder detergent and toilet tissue), and in another one the size was reduced (soft drinks). Another opportunity embraced the creation of two different types of packaging for liquid soap (a reusable one for the first purchase, and another for the refill). The third group of findings indicated the barriers faced by the supermarket to promote such redesigns, as well as the alternatives to mitigate these barriers. Such findings are presented below. Table 2 presents the $1^{\text {st }}$-order and $2^{\text {nd }}$-order codes that resulted from the inductive data analysis.

Table 2 - Findings codification.

\begin{tabular}{|l|l|}
\hline \multicolumn{1}{|c|}{$\mathbf{1}^{\text {st-order codes }}$} & \multicolumn{1}{|c|}{$\mathbf{2}^{\text {nd }}$-order codes } \\
\hline $\begin{array}{l}\text { Desire to combine economic gains with sustainability, } \\
\text { competitive pressures, sustainability and profits, } \\
\text { innovating to generate profit, and meeting requirements. }\end{array}$ & Motivations \\
\hline $\begin{array}{l}\text { Consumer buying habits, understanding customers, } \\
\text { increasing packaging size, reducing packaging size, } \\
\text { refilling the product, and reusable packaging. }\end{array}$ & Opportunities \\
\hline $\begin{array}{l}\text { Commercial doubts that generated barriers, uncertainties } \\
\text { that block the redesign, supplier's rejection, supermarket } \\
\text { conditions that induce rejection, blocking the redesign } \\
\text { dissemination, building barriers to competitors, purchasing } \\
\text { power and mitigation, involvement of suppliers, use of the } \\
\text { position of power, management of the rules, exploration of } \\
\text { the shelf space, and exploration of ordered items. }\end{array}$ & \\
\hline
\end{tabular}




\subsection{Motivations}

The supermarket operates in a price-sensitive market, and consumers of this market do not care about sustainability (managers A, B and D). "They choose a store based on the lowest price offered. Thus, we must reduce our costs. But, how to reduce costs if you do not control your suppliers and consumers? The packaging redesign was an interesting option to reduce costs, as well as to engage suppliers in our redesigns" (manager C). In such a context, a packaging redesign that helps to reduce the price offered to consumers constitutes a top priority for the supermarket chain investigated (A, B, C and D). Without this clear focus a redesign can generate more losses than benefits to the supermarket (A, B and D). "This is not an easy task, since we sell more than 65,000 items" (D).

\subsection{Opportunities}

To redesign packaging the supermarket regularly analyzes thousands of items aiming to identify opportunities for cost reduction, and at the same time for improving the environmental or the social dimensions of sustainability. These analyses encompass the consumers' buying habits. "If most consumers usually buy two packets of an item, why not increase the size of the packaging? Despite its bigger size, the bigger packaging optimizes production processes, transportation, and storage throughout the supply chain (per kilo, liter, or volume of product sold). It can also help to optimize transportation and storage inside the retail store. In sum: the use of slightly bigger packaging is better for the environment" (A). A different logic applies to items that can be sold in smaller packages (single adults and small families constitute groups that usually buy small portions), or for packaging which could be refilled by the consumer $(\mathrm{C})$. The redesigns that generated benefits for the supermarket, its suppliers, and for the environment are presented below. 
The case of the powder detergent constitutes an example of a redesign that increased the packaging size. It started with the analysis of the consumers' buying habits. This indicated that many consumers purchased two cartons rather than one during a single visit to the supermarket. This conclusion suggested that the size of the carton could be increased (A and B). This possibility was presented to the suppliers, who said that the packaging would be developed for the U.S. market due to the buying habits of the American consumers (D). A new package was then developed which was bigger than the old one. An audit performed by the supermarket and its suppliers indicated that the new packaging generated savings on material, energy, transportation, and water per kilo of product sold (A and B). Observations in the stores indicated that the new $2 \mathrm{~kg}$ packaging is currently being sold for the same price as the previous $1 \mathrm{~kg}$ packaging (the $1 \mathrm{~kg}$ packaging price was identified in the old price provided by the supermarket during the documentary analysis). "The new price leveraged sales. Considering the strategic elements, the new packaging is better in economic terms" (D). Details about the strategic elements were not provided. Sales reports indicated that approximately 29,700,000 packs of powder detergent are sold per year. "Considering the huge volume sold, even a small saving constitutes an important contribution to the environment" (B). The results delivered through implementation of the new packaging induced the senior managers to prioritize packaging redesign, thus generating a virtuous cycle in the company (A, B, C, and D).

Another example of the opportunity to increase packaging size was identified for toilet tissue. The analysis of consumers' buying habits showed that an ordinary consumer in Brazil purchases 3 to 4 packages of 8 units in a single visit to the supermarket (A and B). "Such information indicated that Brazilian consumers prefer to buy larger quantities of such product" (A). This finding unveiled a new packaging redesign opportunity (A and B). The supermarket then asked the suppliers to develop larger packages of toilet tissue (A, B and C). The new packaging with 32 units generated small savings in packaging material, storage and transportation (for the suppliers). For the supermarket, the new packaging has reduced storage costs associated with handling and internal transportation. For the supplier, the new packaging reduced the transportation frequency (A, B and C). "The supplier informed us that the new packaging uses a little bit more material, but it saves a lot of material compared 
to the total amount of packaging material used in 3 or 4 packages" (A). Such savings allowed a reduction in the price offered to the consumer, thus leveraging the sales $(C)$. The overall saving is approximately $8 \%$ per meter of toilet paper sold (including the supermarket's and the supplier's savings). Sales reports provided to the researchers indicated that approximately 27,720,000 packs of toilet tissue sales are sold per year (all of them in the new packaging size). According to two senior managers, such numbers motivated the supermarket to keep looking for other opportunities to redesign packaging (A and B).

The reduction in the size of packaging constitutes an interesting opportunity. This was the case for the soft drinks packaging. "In the past, some consumers used to complain at the cash register about the amount of soda included in the 2.51 soft drinks bottles. For them, the bottles were too big" (C). This information suggested that most consumers do not drink all the beverage included in a 2.51 bottle. In such a context, part of the beverage was being left inside the bottle. The consumers' complaints could be associated with the later disposal of the unfinished beverage since, when opened, it loses its properties after some hours (A, B and C). "This possibility could indicate that the bottle was too big for most Brazilian families that drink soda" (A). To reduce the possible discharge of the unconsumed beverage, the supermarket asked the suppliers to develop a smaller bottle (A, B and D). After the introduction of the new bottle (1.75 1), the complaints at the cash register ceased (A and B). Since the 1.751 bottle is smaller than the 2.51 bottle, the new packaging also has reduced the use of raw materials, storage, and transportation per liter of soda actually consumed (A and $\mathrm{D})$. This reduction generated an economic gain (B and $\mathrm{D})$. "The sales of the new bottle increased rapidly, while the sales of the 2.51 have decreased" (C). The sales reports provided to the researchers indicated that approximately $99,000,000$ bottles of the redesigned soft drinks are sold per year. One manager stated: "Can you imagine the amount of beverage that is not discharged by the consumers after the introduction of the new bottle? Unfortunately, we do not have this number" (B). Once again, the increase in sales seems to motivate the supermarket to promote new redesigns (A and B). 
The opportunity for the consumer to reuse packaging also facilitates the potential for a redesign. The supermarket used to offer two types of liquid soap: a branded product (BP) and a private label product (PL). The PL was approximately 50\% cheaper than the BP product $(\mathrm{C})$. The price difference induced most consumers to buy the PL product. However, the PL profit margin was $15 \%$ lower than the profit margin of the BP product. To improve the profit margin, the supermarket asked its suppliers to reduce its cost. This requirement led to the development of two new packaging solutions: a bottle that could be reused and a package for the refill. The new alternative helped to reduce materials, transportation, and storage, since the refill uses smaller and simpler packaging (A and B). These reductions lowered the price offered to the consumer by $75 \%$ compared to that of the original PL product packaging, thus increasing the sales of the PL product (C). The refill also generated higher profits for the supermarket (7\%, compared to the BP profit margin). "The lowest price focus helps to leverage sustainability and still generate profits for the supermarket and its suppliers" (D). Sales reports indicated that approximately 36,300,000 units of liquid soap are sold per year. "Without the refill alternative, the cost and the waste of material used in the former packaging would be higher" (B). "This is an example of the combination of the environmental gains with the economic gains. Such a combination is very important for us" (C).

\subsection{Barriers and their mitigation}

Beyond the barriers associated with the price-sensitive market segment, the new redesigns can face unexpected barriers inside the supermarket. Such barriers are associated with the following doubts: how will price-sensitive consumers perceive the new item? How will the redesigned item affect the sales of other items that are being sold by the supermarket? And how will the larger packaging affect the number of times a consumer visits the supermarket and the amount of money the consumer spends during each visit to the supermarket (A, B, $\mathrm{C}$ and D)? "Clear answers to such questions are required to eliminate the possibility of a reduction in the supermarket sales" (C). 
The suppliers may also reject the changes proposed by the supermarkets, which constitutes another important barrier to the packaging redesign. The rejection arises from two conditions imposed by the supermarket: the suppliers must cover the whole costs resulting from the redesign; and the suppliers have no guarantees regarding the future sales of the redesigned product (A, B, C and D). Beyond that, the suppliers' rejection of the redesigns is reinforced by the temporary exclusivity clause imposed by the supermarket (D). This clause aims to protect the competitive interests of the supermarket by creating a barrier to its competitors (A). The researchers had access to a contract signed by the supplier and the supermarket (during the documentary analysis). According to this contract, the temporary exclusivity clause defines that the improvements, learnings and solutions cannot be transferred to other supermarkets for a specific period of time (a minimum of one year). "This momentary exclusivity constitutes a huge competitive advantage on the price sensitive market segment, but a barrier to the wider dissemination of a redesigned packaging" (C). It is important to note that the exclusivity clause favors only the supermarket. Such a condition reduced the attractiveness of some redesigns for big suppliers due to the lower volume of sales that a single supermarket can have (regardless of its buying power). Such elements limited the number of redesigns conducted by the supermarket and its suppliers (A, B and D).

The huge purchasing power of the supermarket "helped to mitigate the rejection of some suppliers due to the exclusivity clause" (B). To reverse a supplier's rejection of a redesign, the purchasing professionals of the supermarket approach the dissatisfied supplier by using two main arguments: the supermarket may reduce the supplier's sales area/shelf space inside the stores, and the supermarket may reduce the orders or number of items regularly ordered from the supplier. Both conditions may favor the supplier's competitors. This possibility induced some larger suppliers to redesign their packaging (C and D). Some managers interviewed postulated that the existence of a tool that evaluates the supplier's payback could reduce their rejection (A and $\mathrm{B}$ ). This payback evaluation should include the operational and financial aspects associated with the packaging redesign $(C$ and $D)$. 
Observations performed by the middle manager in the company's meetings indicated that the supermarket always highlighted favorable results in the cases listed to other suppliers. To the other researchers' surprise, such results seem to be the motivator that induce the supermarket managers to pursue their own company's sustainability commitments/environmental policy. Beyond the benefits, the supermarket managers used to mention the losses faced by the suppliers that have not cooperated with a packaging redesign proposal. These elements aim to induce other suppliers to present new packaging redesign proposals. The middle manager also observed that all suppliers used to ask the supermarket to remove the exclusivity clause (when asked to engage their companies on a packaging redesign). However, when confronted with the possible losses that a nonengagement can produce, these suppliers' representatives start to discuss alternatives to redesign a certain packaging. In such moments, some representatives used to mention that, for their companies, the supermarket is a customer that deserves special attention.

Figure 3 presents the drivers and barriers identified.

Figure 3 - Drivers and barriers to the packaging redesign

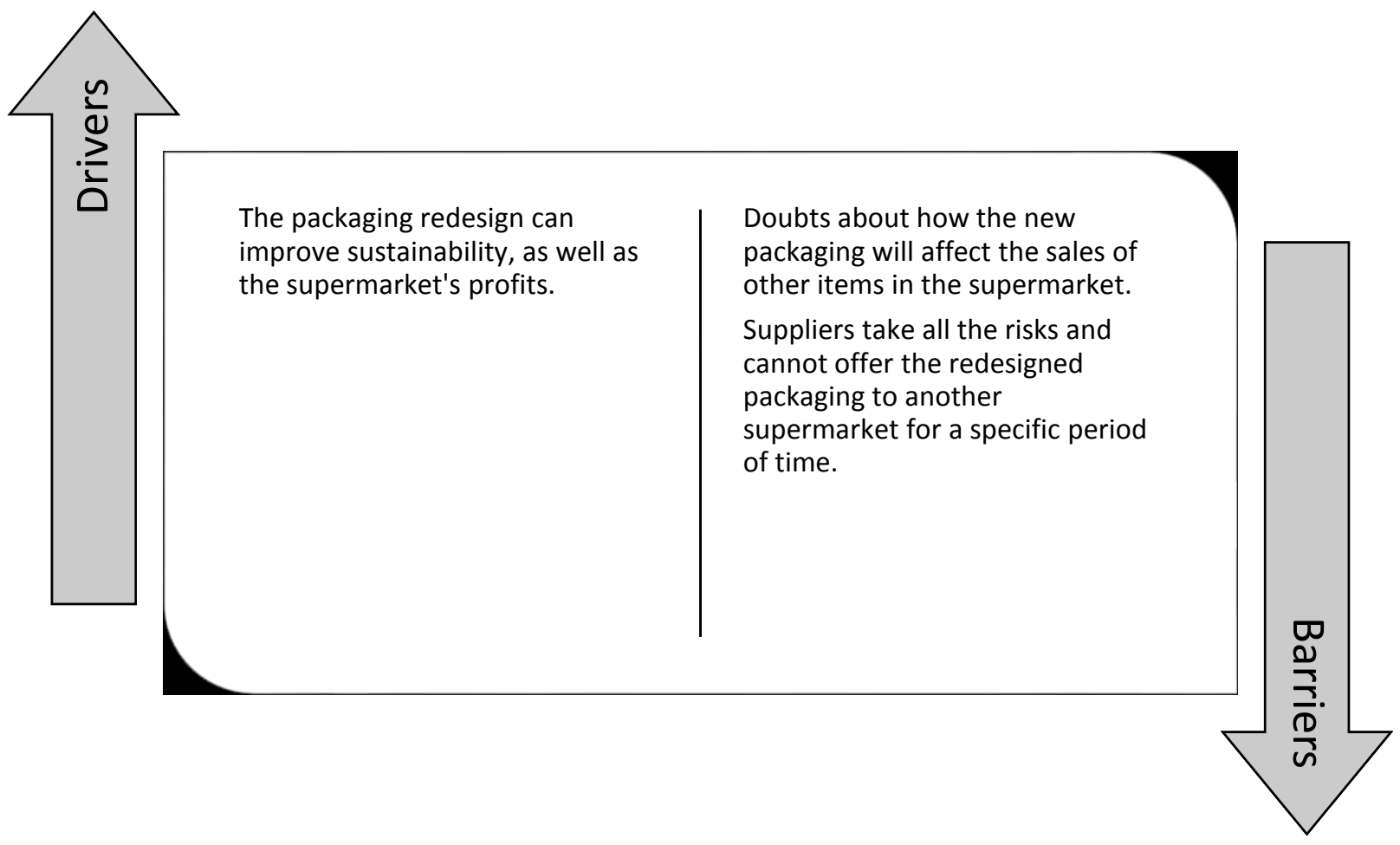




\section{Discussion}

\subsection{Motivations}

The development of alternatives to improve economic gains seems to have motivated the supermarket to focus on sustainable actions. Similar findings were identified across the retail sector (Hyde et al., 2001; Weissbrod and Bocken, 2017), or across the industrial sector (Borchardt et al., 2011). This study contributes by suggesting that the packaging redesign constitutes an interesting option to generate economic gains in the supermarket industry. As identified, the redesigns have helped to reduce the costs associated with waste disposal (Hyde et al., 2001), increase consumer satisfaction (Williams et al., 2008), reduce the total environmental impact, even if there is a slight increase in impact from the packaging itself in some cases (Williams and Wikström, 2011), and to minimize the generation of waste in households and within distribution and retail (Silvenius et al., 2014).

However, the redesign of packaging requires the engagement of suppliers (since the items provided by them have a great impact on the costs incurred by the supermarket). Nevertheless, their engagement may be blocked by the barriers presented in the previous section. In such a context, this study contributes by suggesting the existence of another motivator: the economic gains that arise from the packaging redesign helps to engage suppliers in the supermarket's proposals, or can help to mitigate the early rejection of other suppliers to a packaging redesign. The analysis of this possibility generated the following propositions:

P01 - Companies pay more attention to their own sustainability commitments / environmental policy when the actions towards sustainability developed in the past generated good economic gains.

P02 - Companies that manage to combine economic gains with environmental sustainability present better results on the latter. 
P03 - Companies that manage to combine economic gains with environmental sustainability develop more actions towards sustainability throughout the time.

Further studies could also investigate whether the focus on economic gains improve environmental sustainability outcomes? What barriers hinder such a focus? And how to mitigate these barriers? By answering such questions, academics can help to leverage the companies' motivations. As identified in the supermarket investigated, these motivations may result in new and interesting ways to promote environmental improvement.

\subsection{Opportunities}

To identify opportunities for the redesign of packaging, the retailers could analyze the size of the packaging on items sold in their stores. According to the literature, this packaging may be too big (Hanssen et al., 2017; Wikström et al., 2016; Williams et al., 2012). This seems to be the case for the 2.51 soda bottles. Findings suggest that the reduction of the size of the bottle decreased the use of raw materials, transportation, and storage per liter of product really consumed (since some families used to throw away part of the unconsumed beverage in the bigger bottles). The number of customers travelling to the supermarket also seems to be the same (if we consider the product consumed and the product not wasted). This conclusion suggests that the attention of the retailer to their customers' comments at the cash register may create a long-term thinking culture (Mont et al., 2014), may promote more sustainable consumption (Ritter et al., 2015; Schroeder, 2014; Wang et al., 2014), and may help to reduce food waste (Mena et al., 2014). A tool to provide a better understanding of consumer habits could leverage such benefits. The examination of these possibilities generated the following propositions:

P04 - The analyses of the packaging size and of the consumers' habits unveils opportunities to reduce the amount of materials used. 
P05 - The analyses of the packaging size and of the consumers' habits unveils opportunities to reduce the disposal of unconsumed perishable products.

This study contributes to the literature by suggesting that some packaging may also be too small, which prompts consumers to buy multiple packets in a single visit to the supermarket (see the examples of the toilet paper and powder detergents). Other packaging could be reused (see the example of the liquid soap). The findings also contribute to the literature by suggesting when to increase packaging size, when to reduce it, and when to combine reusable packaging with refills. The packaging size could be increased when most consumers buy more than one packet during a single visit to the supermarket, could be reduced when most consumers discard part of the product without consuming it, or could be changed when it is possible to adopt reusable packaging. The analysis of these possibilities generated the following propositions:

P06 - The increase of the packaging size when most consumers buy more than one package during a single visit to the supermarket helps to reduce the packaging material used per unit sold.

P07 - The reduction of the packaging size when most consumers do not consume the whole content of a perishable product contained within a single package helps to reduce the wastage of such product and to reduce the use of material per unit of product consumed.

P08 - The combination of a reusable packaging with a refill helps to reduce the environmental impact due to the packaging.

P09-Consumers' comments about the products at the cash register can unveil good opportunities to redesign packaging. 
Further studies could also try to develop tools to identify opportunities to redesign packaging among several thousands of items sold in a supermarket. Such tools may consider: the preferences or habits of the local consumers; the amount of money usually spent by the consumer in a single visit to the supermarket; the proportion of product wasted by the consumers; the number of journeys undertaken by the consumer to the supermarket; the sales increase that could be generated by the new design; and the environmental impact resulting from the new design.

\subsection{Barriers and their mitigation}

The consumers in the price sensitive market investigated do not to wish to pay a higher price for a certified product (Thompson et al., 2010). This position prevents supermarkets from offering a fair price based on the value of a green product (Dekhili and Achabou, 2013). The findings of this study suggest that the market segment should be considered based on the analysis of packaging redesign opportunities (Belz and Schmidt-Riediger, 2010).

Some internal barriers that prevent the wider redesign of packaging in the supermarket industry are associated with the doubts expressed by the supermarket's senior managers interviewed (how price sensitive consumers will perceive the new item, how the redesigned item will affect the sales of other items being sold by the supermarket, and how the larger packaging will affect the number of times a consumer visits the supermarket or the amount of money spent during each visit to the supermarket). Such possibilities suggest that commercial uncertainties may block collaboration among the vital actors in the supply chain (Akamp and Müller, 2013; Hyde et al., 2001), may prevent a better relationships beyond the corporate boundaries (Leppelt et al., 2013; Thongplew et al., 2014), or may lead companies to avoid the development of a redesign that could better connect packaging and consumption - as suggested in the literature (Wikström et al., 2014). The analysis of these possibilities generated the following propositions: 
P10 - Uncertainties about the price sensitivity of consumers block the packaging redesigns.

P11 - Uncertainties about how the redesigned item will affect the sales of other items being sold by the supermarket block the packaging redesign.

P12 - Uncertainties about how a larger packaging will affect the number of times a consumer visits the supermarket block the packaging redesign.

P13 - Uncertainties about how a redesign will affect the amount of money spent by the consumer during a visit to the supermarket block the packaging redesign.

These uncertainties can be related to the following questions: how the price-sensitive consumers will perceive the new design? How the new packaging will affect the sales of other items being sold by the supermarket? How the new design will influence the number of times that a consumer visits the supermarket? And how the new design will affect the amount of money spent by the consumer in each visit to the supermarket? Future case studies could investigate how to mitigate such uncertainties. The findings of this case study could allow the development of a future quantitative model that simultaneously evaluates the best alternatives to generate economic and environmental gains. If researchers manage to develop such a systematic approach regarding motivations, opportunities and barriers of packaging redesign, as has been described in this study, perhaps environmental sustainability will start to be leveraged by its current villain - the economic gains. Will it be possible on a large scale? In the supermarket investigated, this seems to be feasible. 
The exclusivity clause imposed by the supermarket to its suppliers is another barrier to the rapid expansion of the redesigned packaging jointly developed by the supermarket and a specific supplier. Because of this clause, a supplier can only offer the redesigned packaging to other supermarket chains after a certain period (a minimum of one year is required by the supermarket). In the meantime, the supplier must cover the costs of the redesign by using solely the sales generated by the supermarket where the redesign was developed. This finding is consistent with other findings presented in the literature, which further contend that the dominant logic of supermarkets appears to be one of cost reduction and profit maximization (Glover et al., 2014). An analysis of the alternatives to mitigate such a position presented by the supermarket seems to be missing. The analysis of these possibilities generated the following proposition:

P14 - Retailers that allow the results of the sustainable actions jointly developed with a supplier to be shared with their competitors face fewer objections to engage the supplier in such actions.

Further studies could also try to identify alternatives to induce the supermarket not to impose such a clause.

The huge purchasing power of the supermarket seems to mitigate the supplier's rejection of a packaging redesign. Two alternatives are used by the supermarket investigated to reverse the rejection of its suppliers: the reduction of the supplier's sales area/shelf space inside the stores and the reduction on orders or the number of items regularly ordered from the supplier. The use of such power appears as an alternative means of influencing its suppliers (Tidy et al., 2016). The analysis of these possibilities generated the following propositions:

P15 - The threat of reduction of a supplier's sales area/shelf space inside the stores induce the supplier to get involved in the new packaging redesigns proposed by the supermarkets. 
P16 - The threat of reduction on future orders induce the suppliers to get involved in the new packaging redesigns proposed by the supermarkets.

Further studies could develop a tool to evaluate the payback that a supplier could get through a packaging redesign. This information would help to mitigate a suppliers' rejection of packaging redesigns proposed by the supermarkets. 


\section{Conclusion}

This study investigated the motivations, opportunities and barriers that retailers face when considering the effective redesign of the packaging of the products they sell. The lessons learned are presented below.

- The greatest motivator found in this study is the economic gains that a packaging redesign can generate (for the supermarket and its suppliers). The findings suggested that the focus on the economic gains also generated environmental benefits, since some things that may damage the environment also may reduce the company's profits.

- The best opportunities to redesign packaging seem to be the adjustment of its size or type, since the sizes or types used in some regions or markets seem not to be the best option to combine economic and environmental gains.

- The barriers to the redesign of packaging result from the commercial uncertainties faced by the supermarket. These uncertainties can be related to the following questions: how the price-sensitive consumers will perceive the new design? How the new packaging will affect the sales of other items being sold by the supermarket? How the new design will influence the number of times that a consumer visits the supermarket? And how the new design will affect the amount of money spent by the consumer on each visit to the supermarket?

- Another barrier identified is the exclusivity clause imposed by the supermarket on its suppliers. Due to this clause, a supplier can only sell a redesigned packaging to another supermarket chain after a certain period of time. However, the huge purchasing power of the supermarket mitigates a supplier's rejection of a packaging redesign.

The contribution of this study also includes: the organization of the main elements currently dispersed in the academic literature that need to be observed in packaging redesign; the detailing of retailers' strategies in order to raise motivations and opportunities, and tackle 
barriers, with their suppliers, to rethink packaging; and the identification of the lesson learned about packaging redesign which are usually not unveiled in related academic studies.

\section{Research limitations}

The findings of this single case study may not be valid in other scenarios (supermarkets of different sizes, commercial foci, or locations). Besides, the involvement of an employee in the data collection, interviews and analysis may affect the information gathered (due to bias, coercion, or interviewees saying things that they know the researchers would like to hear). These constitute important limitations of the study (Flyvbjerg, 2006). Since the researchers were aware of these possible hurdles, they tried to mitigate them during the study. The global presence of the supermarket investigated, its huge purchasing power, and the senior profile of the interviewees helped to mitigate part of these limitations. Other shortcomings were mitigated by guaranteeing anonymity of the company and interviewees, and the chance to check transcripts. Despite the limitations and constraints, the selection of a single supermarket and the inclusion of a middle manager on the research team allowed the research objectives to be achieved, and to present findings that might be transferrable to other supermarket chains. 


\section{Appendix A - Questions posed to the interviewees}

1. How your supermarket could simultaneously decrease food losses and environmental impact generated by packaging?

2. How your supermarket could better understand the consumers' habits and perceptions to unveil opportunities to redesign packaging?

3. How a supermarket can induce its suppliers to redesign the packaging?

4. Could you mention the drivers and barriers faced by your supermarket when trying to redesign packaging in conjunction with your suppliers?

5. How do you evaluate the following topic in the supermarkets supply chain (transparency of demand information, quality management, process controls, shelf-life management and packaging design)?

6. How each one of these topics could be improved?

7. How could a supermarket mitigate the undesired impacts of the packaging that the consumer noted as being too big and packaging that were difficult to empty, and wastage because of passed "best before date"?

8. How to mitigate the undesired impacts of lower packaging resulting in transportation (increase on the work, emissions and energy consumption)? 


\section{References}

Akamp, M., Müller, M., 2013. Supplier management in developing countries. J. Clean. Prod. 56, 5462. doi:http://dx.doi.org/10.1016/j.jclepro.2011.11.069

Almeida, C.M.V.B., Rodrigues, A.J.M., Agostinho, F., Giannetti, B.F., 2017. Material selection for environmental responsibility: the case of soft drinks packaging in Brazil. J. Clean. Prod. 142, 173-179. doi:10.1016/j.jclepro.2016.04.130

Almeida, C.M.V.B., Rodrigues, A.J.M., Bonilla, S.H., Giannetti, B.F., 2010. Emergy as a tool for Ecodesign: evaluating materials selection for beverage packages in Brazil. J. Clean. Prod. 18, 32-43. doi:10.1016/j.jclepro.2009.03.019

Beitzen-Heineke, E.F., Balta-Ozkan, N., Reefke, H., 2017. The prospects of zero-packaging grocery stores to improve the social and environmental impacts of the food supply chain. J. Clean. Prod. 140, 1528-1541. doi:10.1016/j.jclepro.2016.09.227

Belz, F.-M., Schmidt-Riediger, B., 2010. Marketing strategies in the age of sustainable development: Evidence from the food industry. Bus. Strateg. Environ. 19, 401-416. doi:10.1002/bse.649

Bertolini, M., Bottani, E., Vignali, G., Volpi, A., 2016. Comparative Life Cycle Assessment of Packaging Systems for Extended Shelf Life Milk. Packag. Technol. Sci. 29, 525-546. doi:10.1002/pts.2235

Borchardt, M., Wendt, M.H., Pereira, G.M., Sellitto, M.A., 2011. Redesign of a component based on ecodesign practices: Environmental impact and cost reduction achievements. J. Clean. Prod. 19, 49-57.

Dekhili, S., Achabou, M.A., 2013. Price Fairness in the Case of Green Products: Enterprises' Policies and Consumers' Perceptions. Bus. Strateg. Environ. 22, 547-560. doi:10.1002/bse.1763

Del Borghi, A., Gallo, M., Strazza, C., Del Borghi, M., 2014. An evaluation of environmental sustainability in the food industry through Life Cycle Assessment: The case study of tomato products supply chain. J. Clean. Prod. 78, 121-130. doi:10.1016/j.jclepro.2014.04.083

Delai, I., Takahashi, S., 2013. Corporate sustainability in emerging markets: Insights from the practices reported by the Brazilian retailers. J. Clean. Prod. 47, 211-221.

Dominic, C.A.S., Östlund, S., Masoud, M.M., 2015. Towards a conceptual sustainable packaging development model: A corrugated box case study. Packag. Technol. Sci. 28, 397-413. doi:10.1002/pts.2113

Eisenhardt, K.M., Graebner, M.E., 2007. Theory building from cases: Opportunities and challenges. Acad. Manag. J. 50, 25-32.

Erol, I., Cakar, N., Erel, D., Sari, R., 2009. Sustainability in the Turkish retailing industry. Sustain. Dev. 17, 49-67. doi:10.1002/sd.369

Flyvbjerg, B., 2006. Five Misunderstandings About Case-Study Research. Qual. Inq. 12, 219-245. doi:10.1177/1077800405284363

Gibbert, M., Ruigrok, W., 2010. The "What" and "How" of Case Study Rigor: Three Strategies Based on Published Work. Organ. Res. Methods 13, 710-737.

Glover, J.L., Champion, D., Daniels, K.J., Dainty, A.J.D., 2014. An Institutional Theory perspective on sustainable practices across the dairy supply chain. Int. J. Prod. Econ. 152, 102-111. doi:10.1016/j.ijpe.2013.12.027 
Grönman, K., Soukka, R., Järvi-Kääriäinen, T., Katajajuuri, J.M., Kuisma, M., Koivupuro, H.-K., Ollila, M., Pitkänen, M., Miettinen, O., Silvenius, F., Thun, R., Wessman, H., Linnanen, L., 2013. Framework for sustainable food packaging design. Packag. Technol. Sci. 26, 187-200. doi:10.1002/pts.1971

Hampl, N., Loock, M., 2013. Sustainable Development in Retailing: What is the Impact on Store Choice? Bus. Strateg. Environ. 22, 202-216. doi:10.1002/bse.1748

Hanssen, O.J., Vold, M., Schakenda, V., Tufte, P.-A., Møller, H., Olsen, N.V., Skaret, J., 2017. Environmental profile, packaging intensity and food waste generation for three types of dinner meals. J. Clean. Prod. 142, 395-402. doi:10.1016/j.jclepro.2015.12.012

Hyde, K., Smith, A., Smith, M., Henningsson, S., 2001. Challenge of waste minimization in the food and drink industry: A demonstration project in East Anglia, UK. J. Clean. Prod. 9, 57-64. doi:10.1016/S0959-6526(00)00050-0

Ingrao, C., Gigli, M., Siracusa, V., 2017. An attributional Life Cycle Assessment application experience to highlight environmental hotspots in the production of foamy polylactic acid trays for fresh-food packaging usage. J. Clean. Prod. 150, 93-103. doi:10.1016/j.jclepro.2017.03.007

Jones, P., Comfort, D., Hillier, D., Eastwood, I., 2005. Retailers and sustainable development in the UK. Int. J. Retail Distrib. Manag. 33, 207-214. doi:10.1108/09590550510588370

Kowalkowski, C., Witell, L., Gustafsson, A., 2013. Any way goes: Identifying value constellations for service infusion in SMEs. Ind. Mark. Manag. 42, 18-30. doi:10.1016/j.indmarman.2012.11.004

Lee, S.G., Xu, X., 2005. Design for the environment: life cycle assessment and sustainable packaging issues. Int. J. Environ. Technol. Manag. 5, 14. doi:10.1504/IJETM.2005.006505

Leppelt, T., Foerstl, K., Reuter, C., Hartmann, E., 2013. Sustainability management beyond organizational boundaries-sustainable supplier relationship management in the chemical industry. J. Clean. Prod. 56, 94-102. doi:10.1016/j.jclepro.2011.10.011

Lewis, H., Verghese, K., Fitzpatrick, L., 2010. Evaluating the sustainability impacts of packaging: The plastic carry bag dilemma. Packag. Technol. Sci. 23, 145-160. doi:10.1002/pts.886

Mayring, P., 2014. Qualitative Content Analysis: Theoretical Foundation, Basic Procedures and Software Solution. Beltz Verlag, Klagenfurt.

Mayring, P., 2003. Qualitative Inhaltsanalyse. Grundlagen und Techniken (Qualita-tive Content Analysis. Principles and Techniques), eighth ed. ed. Beltz Verlag, Weinheim.

Mena, C., Terry, L.A., Williams, A., Ellram, L., 2014. Causes of waste across multi-tier supply networks: Cases in the UK food sector. Int. J. Prod. Econ. 152, 144-158. doi:10.1016/j.ijpe.2014.03.012

Mont, O., Neuvonen, A., Lähteenoja, S., 2014. Sustainable lifestyles 2050: Stakeholder visions, emerging practices and future research. J. Clean. Prod. 63, 24-32. doi:10.1016/j.jclepro.2013.09.007

Nordin, N., Selke, S., 2010. Social aspect of sustainable packaging. Packag. Technol. Sci. 23, 317326. doi:10.1002/pts. 899

Prakash, G., Pathak, P., 2017. Intention to buy eco-friendly packaged products among young consumers of India: A study on developing nation. J. Clean. Prod. 141, 385-393. doi:10.1016/j.jclepro.2016.09.116 
Riegel, I.C., Staudt, D., Daroit, D., 2012. Identification of environmental aspects associated to the production of perfumery packaging - Contribution to sustainable projects [Identificação de aspectos ambientais relacionados à produção de embalagens de perfumaria - Contribuição para projetos suste. Gest. e Prod. 19, 633-645. doi:10.1590/S0104-530X2012000300014

Ritter, Á.M., Borchardt, M., Vaccaro, G.L.R., Pereira, G.M., Almeida, F., 2015. Motivations for promoting the consumption of green products in an emerging country: exploring attitudes of Brazilian consumers. J. Clean. Prod. 106, 507-520. doi:10.1016/j.jclepro.2014.11.066

Saldaña, J., 2015. The coding manual for qualitative researchers. Sage.

Saunders, M., Lewis, P., Thornhill, A., 2009. Research Methods for Business Students. Pearson Education Ltd., Harlow.

Savin-Baden, M., Major, C.H., 2013. Qualitative research: The essential guide to theory and practice. Routledge.

Schroeder, P., 2014. Assessing effectiveness of governance approaches for sustainable consumption and production in China. J. Clean. Prod. 63, 64-73. doi:10.1016/j.jclepro.2013.05.039

Seawright, J., Gerring, J., 2008. Case Selection Techniques in Case Study Research: A Menu of Qualitative and Quantitative Options. Polit. Res. Q. 61, 294-308. doi:10.1177/1065912907313077

Silvenius, F., Grönman, K., Katajajuuri, J.M., Soukka, R., Koivupuro, H.K., Virtanen, Y., 2014. The role of household food waste in comparing environmental impacts of packaging alternatives. Packag. Technol. Sci. 27, 277-292. doi:10.1002/pts.2032

Sohrabpour, V., Oghazi, P., Olsson, A., 2016. An Improved Supplier Driven Packaging Design and Development Method for Supply Chain Efficiency. Packag. Technol. Sci. 29, 161-173. doi:10.1002/pts.2194

SPC, 2011. Definition of Sustainable Packaging [WWW Document]. Sustain. Packag. Coalit. URL https://sustainablepackaging.org/wp-content/uploads/2017/09/Definition-of-SustainablePackaging.pdf (accessed 10.25.17).

Styles, D., Schoenberger, H., Galvez-Martos, J.-L., 2012. Environmental improvement of product supply chains: Proposed best practice techniques, quantitative indicators and benchmarks of excellence for retailers. J. Environ. Manage. 110, 135-150.

doi:http://dx.doi.org/10.1016/j.jenvman.2012.05.021

Thompson, D.W., Anderson, R.C., Hansen, E.N., Kahle, L.R., 2010. Green segmentation and environmental certification: Insights from forest products. Bus. Strateg. Environ. 19, 319-334. doi:10.1002/bse. 647

Thongplew, N., Van Koppen, C.S.A., Spaargaren, G., 2014. Companies contributing to the greening of consumption: Findings from the dairy and appliance industries in Thailand. J. Clean. Prod. 75, 96-105. doi:10.1016/j.jclepro.2014.03.076

Tidy, M., Wang, X., Hall, M., 2016. The role of Supplier Relationship Management in reducing Greenhouse Gas emissions from food supply chains: supplier engagement in the UK supermarket sector. J. Clean. Prod. 112, 3294-3305. doi:http://dx.doi.org/10.1016/j.jclepro.2015.10.065

Verghese, K., Lewis, H., Lockrey, S., Williams, H., 2015. Packaging's Role in Minimizing Food Loss and Waste Across the Supply Chain. Packag. Technol. Sci. 28, 603-620. doi:10.1002/pts.2127 
Wang, P., Liu, Q., Qi, Y., 2014. Factors influencing sustainable consumption behaviors: A survey of the rural residents in China. J. Clean. Prod. 63, 152-165. doi:10.1016/j.jclepro.2013.05.007

Wang, Z., Mathiyazhagan, K., Xu, L., Diabat, A., 2016. A decision making trial and evaluation laboratory approach to analyze the barriers to Green Supply Chain Management adoption in a food packaging company. J. Clean. Prod. 117, 19-28. doi:10.1016/j.jclepro.2015.09.142

Weissbrod, I., Bocken, N.M.P., 2017. Developing sustainable business experimentation capability A case study. J. Clean. Prod. 142, 2663-2676. doi:10.1016/j.jclepro.2016.11.009

Wikström, F., Williams, H., Venkatesh, G., 2016. The influence of packaging attributes on recycling and food waste behaviour - An environmental comparison of two packaging alternatives. J. Clean. Prod. 137, 895-902. doi:10.1016/j.jclepro.2016.07.097

Wikström, F., Williams, H., Verghese, K., Clune, S., 2014. The influence of packaging attributes on consumer behaviour in food-packaging life cycle assessment studies - A neglected topic. J. Clean. Prod. 73, 100-108. doi:10.1016/j.jclepro.2013.10.042

Williams, H., Wikstr?m, F., L?fgren, M., 2008. A life cycle perspective on environmental effects of customer focused packaging development. J. Clean. Prod. 16, 853-859. doi:10.1016/j.jclepro.2007.05.006

Williams, H., Wikström, F., 2011. Environmental impact of packaging and food losses in a life cycle perspective: A comparative analysis of five food items. J. Clean. Prod. 19, 43-48. doi:10.1016/j.jclepro.2010.08.008

Williams, H., Wikström, F., Otterbring, T., Löfgren, M., Gustafsson, A., 2012. Reasons for household food waste with special attention to packaging. J. Clean. Prod. 24, 141-148. doi:10.1016/j.jclepro.2011.11.044

Yin, R.K., 2009. Case study research: Design and methods, Thousand Oaks, CA: Sage Publications. Sage Publications, Thousand Oaks, CA, CA. 